\title{
Marketing assessment of innovation potential of water filter manufacturers
}

\author{
Tatyana Burtseva ${ }^{1,2, *}$, Nataliya Mironova ${ }^{3,4}$,Elena Volk $^{5}$, and Alexey Chaykovskiy ${ }^{6}$ \\ ${ }^{1}$ Vyatka State University, 610000, Moskovskaya str., 36, Kirov, Russia \\ ${ }^{2}$ Moscow Witte University, 115432, 2nd Kozhukhovsky passage, 12, Moscow, Russia \\ ${ }^{3}$ Perm State Institute of Culture, 614000, Gazeta Zvezda St., 18, Perm, Russia \\ ${ }^{4}$ Perm State Agro-Technological University named after Academician D.N. Pryanishnikov, 614990, \\ Petropavlovskaya str., 23, Perm, Russia \\ ${ }^{5}$ Perm State University, 614990, Bukireva str., 15, Perm, Russia \\ ${ }^{6}$ Plekhanov Russian University of Economics, Stremyanny per., 36, Moscow, Russian Federation
}

\begin{abstract}
The study focuses on analyzing the products of water filter manufacturers using marketing tools. In the course of the study, factorial, cluster, regression analysis, as well as multivariate scaling were used. As a result, it was revealed that $65 \%$ of buyers rely on 4 main factors when buying filter products: price-value ratio, assortment depth, assortment saturation, and advertising support.
\end{abstract}

\section{Introduction}

Innovative changes in any manufacturing enterprise ultimately involve changes in the output, quality, cost, or functional characteristics. Despite the fact that modern process management pursues the goal of reducing production costs, often a by-result is a reduction in the duration of production cycles and the size of the produced batches. This makes it possible to expand the assortment policy.

Assortment policy from the point of view of production efficiency and costeffectiveness of spending should be to determine for a certain period of time the size of the optimal range of products, after which it should be improved by updating. At the same time, the optimal range of goods should ensure, in the conditions of the existing material and technical base of trade, the most complete satisfaction of the population's demand in terms of volume and structure, the maximum sale of goods with a minimum of distribution and consumption costs.

All actions of specialists in the field of product assortment management should be based on reliable information obtained using modern methods of information processing, which make it possible to establish the degree of its statistical reliability. Marketing information processing methods include arithmetic operations, statistical methods, graphical processing, forecasts, operations research methods.

Marketing, being an activity aimed at solving practical business problems, does not provide the development of special mathematical methods and models, but at the same

\footnotetext{
*Corresponding author: burtseva10@mail.ru
} 
time, solving practical marketing problems is impossible without the use of formalized approaches. To solve management problems, modern marketing uses a wide range of marketing models. We consider only those of them that allow an enterprise to realistically assess the market situation in order to develop an effective strategy of behavior (Table 1).

Table 1. Statistical methods of processing marketing research data in the framework of product assortment management.

\begin{tabular}{|c|c|}
\hline Method & Objective \\
\hline \multicolumn{2}{|r|}{1 stage. Analysis of current marketing situation } \\
\hline Regression analysis & $\begin{array}{l}\text { Determination of the customers' attitude to the manufacturer depend on the } \\
\text { main indicators of the assortment. }\end{array}$ \\
\hline $\begin{array}{l}\text { Discriminant } \\
\text { analysis }\end{array}$ & $\begin{array}{l}\text { Determining the attitude of consumers to the manufacturer by evaluating } \\
\text { the products of manufacturers of filter products. }\end{array}$ \\
\hline $\begin{array}{l}\text { Multivariate } \\
\text { scaling }\end{array}$ & Building a perception map of filter products. \\
\hline \multicolumn{2}{|r|}{2 stage. Assortment planning } \\
\hline $\begin{array}{l}\text { Risk assessment } \\
\text { and analysis } \\
\text { methods }\end{array}$ & $\begin{array}{l}\text { Assessment of entrepreneurial risks associated with the introduction of a } \\
\text { new product on the market. }\end{array}$ \\
\hline $\begin{array}{l}\text { Simple } \\
\text { extrapolation }\end{array}$ & Determining demand using exponential smoothing based on actual data \\
\hline \multicolumn{2}{|r|}{3 stage. Assortment concept implementation } \\
\hline Factor analysis & Determination of factors affecting the competitiveness of products. \\
\hline Cluster analysis & $\begin{array}{l}\text { Grouping objects into relatively homogeneous groups, segmenting the } \\
\text { market. }\end{array}$ \\
\hline \multicolumn{2}{|r|}{4 stage. Monitoring results } \\
\hline Joint analysis & $\begin{array}{l}\text { It is used to determine the most optimal ratio of product characteristics in } \\
\text { terms of consumer preferences. }\end{array}$ \\
\hline
\end{tabular}

The recommended technology of using statistical methods for processing marketing research data in the framework of product assortment management has been successfully tested by us in practice in determining the economic effect of using these methods on the example of enterprises in the market of filters and filter elements.

\section{Materials and Methods}

Regression analysis [2] in marketing is used to explain the variation in market shares, sales, brand preference, and other marketing results obtained by managing marketing variables such as advertising, price, distribution, and product quality. Next, a correlation field is built to determine the shape of the relationship between the variables.

Checking the statistical significance of the linear relationship between $\mathrm{X}$ and $\mathrm{Y}$ is performed using hypotheses: $\mathrm{H} 0: \beta 1=0 ; \mathrm{H} 1: \beta 1 \neq 0$

The null hypothesis assumes that there is no linear relationship between $\mathrm{X}$ and $\mathrm{Y}$. Usually a two-way check is done. You can use t-statistics with $\mathrm{n}-2$ degrees of freedom, где $\mathrm{t}=\mathrm{B} / \mathrm{SEв}$

The tightness of the connection is measured by the coefficient of determination $\mathrm{r} 2$ ( 0 to 1). It shows the fraction of the total variation $Y$, which is due to variation $X$. The tightness of the connection is: $\mathrm{r} 2=$ SSregression $/ \mathrm{SSy}=0.926$.

Testing the significance of a relationship is a test of the significance of the coefficient of determination. The hypothesis is: Но: $\mathrm{r} 2$ совокупности $=0 ; \mathrm{H} 1: \mathrm{r} 2$ совокупности $>0$.

The relevant statistic underlying the criterion is the F statistic. 
To estimate the accuracy of the predicted (theoretical) values of $\hat{Y}$, it is useful to calculate the standard error of the estimated regression equation SEE. This statistic represents the standard deviation of the actual $\mathrm{Y}$ values from the predicted $\hat{\mathrm{Y}}$ value.

Discriminant analysis in marketing research can provide answers to the following questions [1]:

- how, in terms of demographic characteristics, store adherents differ from those who do not have this adherence;

- what psychographic characteristics help to distinguish between price-sensitive and price-sensitive buyers of the product;

- do the market segments differ in their preferences;

- what are the differences between regular shoppers of department stores and regular shoppers of small bakeries in terms of lifestyles, etc.

The interpretation of discriminant weights is similar in multiple regression analysis. The value of the coefficient for a particular predictor depends on other predictors included in the discriminant function.

Multivariate scaling is a universal tool for obtaining spatial perception of the analyzed objects.

For the analysis of perception, 13 types of filtering products were evaluated using the procedure of factor analysis of marketing research data in the Minitab 14 program. Initial data is an expert assessment on a 9-point scale of the main assortment components of these products.

When constructing a perception map, objects can be projected onto 2, 3, 4 and even more axes. Based on factor analysis and based on the values of variances of variables, in our example, a decision was made about a two-dimensional space, i.e. the perception map will contain two axes. The map can be interpreted by examining the coordinates and relative positions of the products. Isolated products have their own uniqueness. Gaps in the map can indicate potential opportunities for new product introductions and positioning.

Factor analysis of marketing research data. The main goal of the study is to determine the factors affecting the efficiency and competitiveness of the components of the product range in order to determine the directions of their development. For factor analysis at the first stage, it is necessary to form a set of the most essential components of the assortment that affect the competitiveness of filter products.

Correlation analysis helps to identify relationships between variables. If the variables are closely related to each other, therefore, they should be closely correlated with factors. To determine the number of factors, a "scree" graph is used. The start point of the "scree" reflects the true significance of the factors. To interpret the factors, it is necessary to determine the variables that have high values of the loads for the same factor. If a factor cannot be clearly defined in terms of its relationship with the original variables, then it should be interpreted as undetectable or general (common to all variables).

Cluster analysis of marketing research data can be defined as a method of grouping individuals or objects into relatively homogeneous groups. The selected set of variables should describe the similarity between objects in terms of features relevant to a given marketing research problem. To determine the number of clusters (segments), a dendrogram of "uniting clusters" is built. Assessment and profiling of clusters is based on the average values of cluster objects for each of the variables that form the profile of each object.

Joint analysis is used to determine the most optimal balance of product characteristics from the point of view of consumers. This is especially true when developing new product ideas. As a result of the research, it is possible to determine which of the presented characteristics of the product are of the greatest importance to consumers. The initial data 
for joint analysis is a set of product characteristics, a combination of these characteristics and the attitude of consumers to these characteristics.

\section{Results}

The results of the regression analysis displayed in Table 2. It reflects the consumer assessment of the manufacturer depending on the assortment indicators.

Table 2. The regression analysis results.

\begin{tabular}{|c|c|c|c|c|c|c|}
\hline $\begin{array}{c}\text { Observ } \\
\text { ation }\end{array}$ & $\begin{array}{c}\text { Consumer } \\
\text { assessment } \\
\text { of the } \\
\text { manufactur } \\
\text { er, Y }\end{array}$ & $\begin{array}{c}\text { Number of } \\
\text { purchases } \\
\text { per year, } \\
\mathbf{X}_{1}\end{array}$ & $\begin{array}{l}\text { Assortment } \\
\quad, \mathrm{X}_{2}\end{array}$ & $\begin{array}{c}\text { Product } \\
\text { quality, } \\
\mathbf{X}_{3}\end{array}$ & $\begin{array}{c}\text { Product } \\
\text { price, } \\
\mathbf{X}_{4}\end{array}$ & $\begin{array}{c}\text { Packaging, } \\
\mathrm{X}_{5}\end{array}$ \\
\hline 1 & 6 & 1 & 6 & 8 & 3 & 5 \\
\hline 2 & 9 & 2 & 8 & 9 & 9 & 6 \\
\hline 3 & 8 & 1 & 9 & 7 & 4 & 3 \\
\hline 4 & 3 & 4 & 6 & 4 & 1 & 2 \\
\hline 5 & 8 & 2 & 8 & 6 & 9 & 7 \\
\hline 6 & 4 & 9 & 5 & 3 & 1 & 8 \\
\hline 7 & 5 & 1 & 7 & 6 & 7 & 6 \\
\hline 8 & 2 & 2 & 3 & 4 & 4 & 1 \\
\hline 9 & 9 & 3 & 8 & 9 & 8 & 2 \\
\hline 10 & 5 & 2 & 8 & 7 & 9 & 5 \\
\hline 11 & 7 & 2 & 7 & 9 & 8 & 9 \\
\hline 12 & 2 & 3 & 5 & 3 & 5 & 8 \\
\hline \multicolumn{7}{|c|}{ Corellation matrix } \\
\hline $\mathrm{X}_{1}$ & 0.925 & 1.000 & & & & \\
\hline $\mathrm{X}_{2}$ & 0.835 & 0.809 & 1.000 & & & \\
\hline $\mathrm{X}_{3}$ & 0.845 & 0.834 & 0.688 & 1.000 & & \\
\hline $\mathrm{X}_{4}$ & 0.587 & 0.767 & 0.581 & 0.634 & 1.000 & \\
\hline $\mathrm{X}_{5}$ & 0.062 & 0.191 & 0.073 & -0.007 & 0.243 & 1.000 \\
\hline \multicolumn{7}{|c|}{ Regression Analysis Results } \\
\hline \multicolumn{2}{|c|}{ Regression equation } & \multicolumn{5}{|c|}{$\begin{array}{c}\mathrm{Y}=0.460+0.199 \mathrm{X}_{1}+0.302 \mathrm{X}_{2}+0.230 \mathrm{X}_{3}-0.225 \mathrm{X}_{4}- \\
0.038 \mathrm{X}_{5}\end{array}$} \\
\hline \multicolumn{2}{|c|}{$\begin{array}{l}\text { Checking statistical } \\
\text { significance }\end{array}$} & \multicolumn{3}{|c|}{$\mathrm{t}=\mathrm{b} / \mathrm{SE}_{\mathrm{b}}$} & \multicolumn{2}{|c|}{ ( } \\
\hline \multicolumn{2}{|c|}{ Relation tightness } & \multicolumn{3}{|c|}{$\mathrm{r}^{2}=\left(\mathrm{Y}_{\mathrm{i}}-\mathrm{Y}_{\mathrm{cp}}\right) / \sum\left(\mathrm{Y}_{\mathrm{i}}-\mathrm{Y}_{\mathrm{cp}}\right)^{2}$} & \multicolumn{2}{|c|}{0.926} \\
\hline \multicolumn{2}{|c|}{ Significance of relation } & \multicolumn{3}{|c|}{$\mathrm{F}=\mathrm{SS}_{\mathrm{per}} /\left(\mathrm{SS}_{\text {oct }} /(\mathrm{n}-2)\right)$} & \multicolumn{2}{|c|}{15.02} \\
\hline \multicolumn{2}{|c|}{ Forecasting accuracy } & \multicolumn{3}{|c|}{$\mathrm{SEE}=\sqrt{\mathrm{SS}_{\mathrm{oct}} /(\mathrm{n}-2)}$} & \multicolumn{2}{|c|}{1.338} \\
\hline
\end{tabular}

The probability plot is presented on Figure 1.

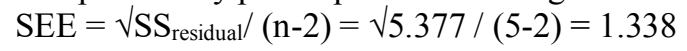

SEE can be interpreted as a kind of mean residual or mean prediction error $\mathrm{Y}$ from a regression equation. The calculation error is not large (1.338), which indicates the accuracy of the study.

Thus, on the basis of regression analysis, it was determined that the quality of the offered products has the most significant influence on the consumer assessment of the manufacturer of water filter products, while packaging has the least influence. 


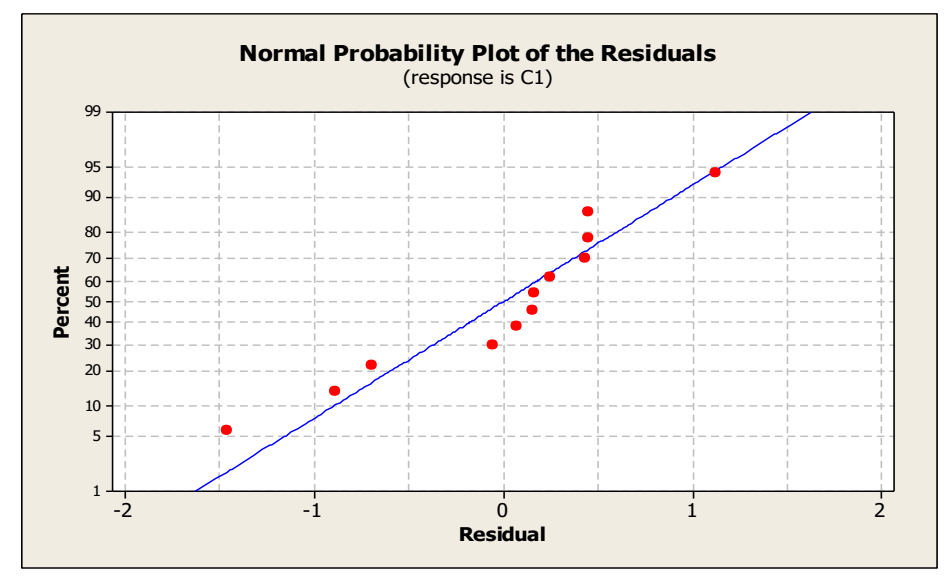

Fig. 1. The probability plot.

The analysis of the consumer assessment of the manufacturer is assessed on the example of three water filter manufacturers Aquafor (A), Barrier (B), Geiser (G). The results of the analysis are presented in Table 3.

Table 3. The discriminant analysis results.

\begin{tabular}{|c|c|c|c|c|c|}
\hline \multicolumn{6}{|c|}{ Manufacturer A } \\
\hline $\begin{array}{l}\text { Product } \\
\text { purchas } \\
\text { e }\end{array}$ & $\begin{array}{c}\text { Annual } \\
\text { family } \\
\text { income } \\
\text { (thousand } \\
\text { rubles) }\end{array}$ & $\begin{array}{c}\text { Consumer } \\
\text { assessment of } \\
\text { the } \\
\text { manufacturer } \\
\text { (9-point scale) }\end{array}$ & $\begin{array}{c}\text { Age } \\
\text { (years) }\end{array}$ & $\begin{array}{c}\text { Family size } \\
\text { (people) }\end{array}$ & $\begin{array}{c}\text { Influence of } \\
\text { advertising (9- } \\
\text { point scale) }\end{array}$ \\
\hline \multicolumn{6}{|c|}{ Average values within the group } \\
\hline 1 & 1600 & 5.4 & 40.6 & 4.3 & 4.4 \\
\hline 2 & 1486 & 4.3 & 42.7 & 2.8 & 5.1 \\
\hline $\begin{array}{c}\text { Generall } \\
\mathrm{y}\end{array}$ & 1546 & 4.9 & 41.7 & 3.6 & 4.7 \\
\hline \multicolumn{6}{|c|}{ Standard deviation in groups } \\
\hline 1 & 5.90 & 0.50 & 1.10 & 0.70 & 0.30 \\
\hline 2 & 6.00 & 0.60 & 1.00 & 0.80 & 0.40 \\
\hline $\begin{array}{c}\text { Generall } \\
\mathrm{y}\end{array}$ & 5.95 & 0.55 & 1.05 & 0.75 & 0.35 \\
\hline \multicolumn{6}{|c|}{ Classification results for the cases selected for analysis } \\
\hline & Actual group & \multicolumn{2}{|c|}{ Number of cases } & Forecasted group -1 & Affiliation, $\%$ \\
\hline Group & 1 & \multirow{2}{*}{\multicolumn{2}{|c|}{$\begin{array}{l}15 \\
15\end{array}$}} & $12(80 \%)$ & $3(20 \%)$ \\
\hline Group & 2 & & & $14(93 \%)$ & $1(7 \%)$ \\
\hline \multicolumn{5}{|c|}{ Percentage of cases correctly classified by group } & $86.7 \%$ \\
\hline \multicolumn{6}{|c|}{$\begin{array}{l} \\
\end{array}$ Manufacturer B } \\
\hline 1 & 171.7 & 5.5 & 33.8 & 3.6 & 5.2 \\
\hline 2 & 169.2 & 4.2 & 48.4 & 3.1 & 4.9 \\
\hline $\begin{array}{c}\text { Generall } \\
\mathrm{y}\end{array}$ & 170.3 & 4.8 & 42.1 & 3.3 & 5.0 \\
\hline \multicolumn{6}{|c|}{ Standard deviation in groups } \\
\hline 1 & 1.42 & 0.74 & 8.22 & 0.28 & 0.20 \\
\hline 2 & 1.09 & 0.56 & 6.29 & 0.22 & 0.15 \\
\hline $\begin{array}{c}\text { Generall } \\
\mathrm{y}\end{array}$ & 1.25 & 0.65 & 7.25 & 0.25 & 0.17 \\
\hline \multicolumn{6}{|c|}{ Classification results for the cases selected for analysis } \\
\hline & Actual gro & \begin{tabular}{l|l} 
& Number of \\
\end{tabular} & & casted group -1 & Affiliation, \% \\
\hline
\end{tabular}




\begin{tabular}{|c|c|c|c|c|c|}
\hline Group & 1 & \multicolumn{2}{|c|}{13} & $9(69 \%)$ & $4(31 \%)$ \\
\hline Group & 2 & 17 & & $14(82 \%)$ & $3(18 \%)$ \\
\hline \multicolumn{5}{|c|}{ Percentage of cases correctly classified by group } & $76.7 \%$ \\
\hline \multicolumn{6}{|c|}{$\begin{array}{ll}\text { Manufacturer G } \\
\end{array}$} \\
\hline 1 & 184.6 & 4.8 & 47.1 & 4.3 & 5.3 \\
\hline 2 & 127.8 & 4.3 & 35.9 & 4.9 & 5.5 \\
\hline Generall & & & \multirow[b]{2}{*}{41.5} & & \\
\hline $\mathrm{y}$ & 156.2 & 4.6 & & 4.6 & 5.4 \\
\hline \multicolumn{6}{|c|}{ Standard deviation in groups } \\
\hline 1 & 28.38 & 0.23 & 5.63 & 0.27 & 0.07 \\
\hline 2 & 28.38 & 0.23 & 5.63 & 0.27 & 0.07 \\
\hline Generall & & & \multirow[b]{2}{*}{5.63} & & \\
\hline $\mathrm{y}$ & $28.38 \quad 1$ & 0.23 & & 0.27 & 0.07 \\
\hline \multicolumn{6}{|c|}{ Classification results for the cases selected for analysis } \\
\hline & Actual group & \multicolumn{2}{|c|}{ Number of cases } & Forecasted group -1 & $\begin{array}{c}\text { Affiliation, } \\
\%\end{array}$ \\
\hline Group & 1 & \multicolumn{2}{|c|}{15} & $14(93 \%)$ & $1(7 \%)$ \\
\hline Group & \multirow{2}{*}{$\begin{array}{c}2 \\
\text { Percentage }\end{array}$} & \multicolumn{2}{|c|}{15} & \multirow{2}{*}{$\frac{15(100 \%)}{\text { group }}$} & $0(0 \%)$ \\
\hline & & ases corre & las & & $96.7 \%$ \\
\hline
\end{tabular}

After examining the group means and standard deviations, it turned out that the variable "income" made the largest contribution to dividing the population into two groups. In addition, it turned out that "the importance of consumer assessment of the manufacturer" is more important for distinguishing between groups than the "influence of advertising". Buyers vary greatly by age, which explains the range of opinions. The main factor that shows the consumer assessment of the manufacturer is the "number of purchases". This factor is common for all manufacturers and does not carry essential information.

Analyzing the consumers of Manufacturer A, we conclude that in discrimination between the "consumer / non-consumer" groups, the most important indicators are "family size" and "advertising influence", with an efficiency rate or percentage of correctly classified cases of $86.7 \%$. For Manufacturer B, such indicators are "family size" and "consumer assessment of the manufacturer", with an efficiency factor of $76.7 \%$. Consumers of Manufacturer B differ to a greater extent in terms of the characteristics of "advertising influence" and "consumer assessment of the manufacturer", with an efficiency rate of $96.7 \%$. Since the excess of the classification accuracy over the random classification is over $25 \%$, therefore, the reliability of the discriminant analysis is assessed as satisfactory.

Multivariate scaling results are presented in Table 4.

Table 4. The multivariate scaling results.

\begin{tabular}{|c|l|c|c|}
\hline \multicolumn{2}{|c|}{ Parameters } & $\begin{array}{c}\text { Axis 1: "Price- } \\
\text { value ratio" }\end{array}$ & $\begin{array}{c}\text { Axis 2: "Assortment } \\
\text { Depth" }\end{array}$ \\
\hline $\mathrm{A}_{1}$ & Quality & 0.687 & 0.349 \\
\hline $\mathrm{A}_{2}$ & Warranty period & -0.429 & -0.379 \\
\hline $\mathrm{A}_{3}$ & Excipients & 0.294 & 0.632 \\
\hline $\mathrm{A}_{4}$ & Packaging & -0.498 & 0.360 \\
\hline $\mathrm{A}_{5}$ & Size, shape & 0.562 & -0.469 \\
\hline $\mathrm{A}_{6}$ & Price & -0.577 & 0.253 \\
\hline $\mathrm{A}_{7}$ & Advertisement & -0.165 & 0.170 \\
\hline $\mathrm{A}_{8}$ & Shelf life & 0.266 & 0.788 \\
\hline $\mathrm{A}_{9}$ & Competitiveness & -0.462 & 0.409 \\
\hline $\mathrm{A}_{10}$ & Varieties & -0.400 & 0.608 \\
\hline $\mathrm{A}_{11}$ & $\begin{array}{l}\text { Environmental friendliness of raw } \\
\text { materials }\end{array}$ & -0.593 & -0.058 \\
\hline $\mathrm{A}_{12}$ & Taste of water after filtration & 0.784 & 0.277 \\
\hline
\end{tabular}




\section{Discussion}

Thus, the analysis revealed the main components of the assortment that affect the competitiveness of filter products:

$\mathrm{X}_{1}$ - Price-value ratio

$\mathrm{X}_{2}-$ Assortment depth

$\mathrm{X}_{3}$ - Packaging attractivity

$\mathrm{X}_{4}-$ Comfort of packaging

$\mathrm{X}_{5}$ - Environmental friendliness of raw materials

$\mathrm{X}_{6}$ - Manufacturer's fame

$\mathrm{X}_{7}$ - Raw materials quality

$\mathrm{X}_{8}-$ Availability of goods in stores

$\mathrm{X}_{9}-$ Shelf life

$\mathrm{X}_{10}-$ Assortment saturation

Interpretation of factors is based on factor loadings. Analyzing the model of factors, we concluded that a relatively high value of correlation for the first factor is observed between variables $X_{2}, X_{7}, X_{13}$, and $X_{16}$. These variables can be combined by the name of the factor "Product competitiveness".

The second factor most of all correlates with the variables $X_{11}$ and $X_{12}$. A higher value of the variable $\mathrm{X}_{12}$ indicates that the formation of the assortment largely depends on the production capabilities of the enterprise. Therefore, the second factor can be called "Manufacturer's potential".

As a result of the conducted factor analysis, the main assortment components of competitiveness factors that determine its importance have been identified. For the formation of the competitiveness of products, the most important are assortment factors such as the depth of the assortment, the influence of the range of competitors, the quality of raw materials, discounts, as well as the qualifications of personnel and production potential.

Table 5. The factor analysis result.

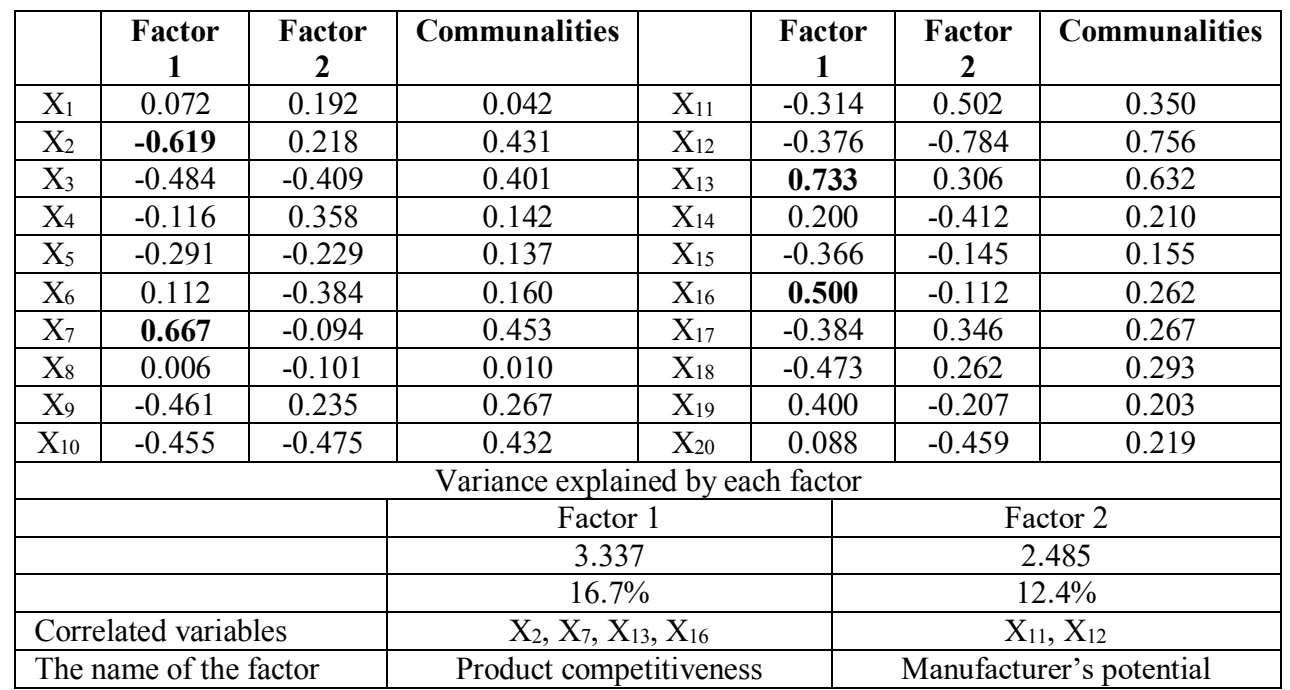

Based on Figure 2, a decision is made on the number of clusters (segments). The initial number of clusters in our case is 3 . 


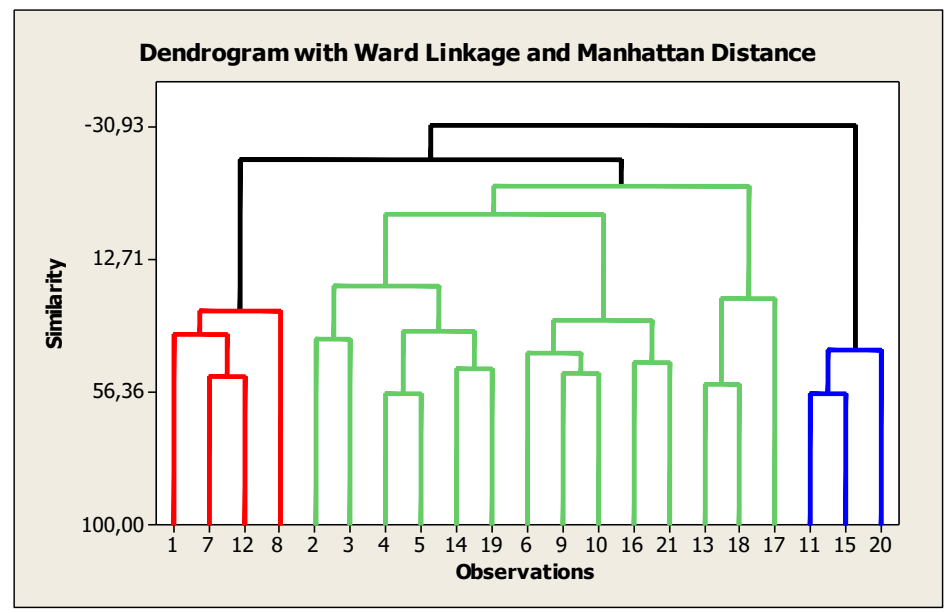

Fig. 2. Dendrogram "cluster merging".

The resulting clusters vary widely in size. The second cluster stands out especially, which covers $65 \%$ of the sample. Thus, Cluster 1 includes consumers who believe that the main assortment factors affecting the competitiveness of products are $\mathrm{X}_{3}, \mathrm{X}_{5}, \mathrm{X}_{10}, \mathrm{X}_{12}, \mathrm{X}_{14}$ and $\mathrm{X}_{20}$. Cluster 2 includes consumers who identify the following assortment factors that affect the competitiveness of products $-\mathrm{X}_{1}, \mathrm{X}_{2}$ and $\mathrm{X}_{15}$. Cluster 3 included the least number of buyers $(15 \%)$, whose answers are not informative in terms of specific indicators of the assortment, nevertheless, who believe that the main factors that form the competitiveness of products are $-\mathrm{X}_{7}, \mathrm{X}_{13}$ and $\mathrm{X}_{16}$.

\section{Conclusion}

Since the second cluster included the largest number of consumers $(65 \%)$, the factors that they identified are the most important assortment indicators that form the competitiveness of products. These are $\mathrm{X}_{1}$ (price-value ratio), $\mathrm{X}_{2}$ (assortment depth), $\mathrm{X}_{10}$ (assortment saturation) and $\mathrm{X}_{15}$ (advertising support). Manufacturers should pay special attention to these factors when developing various measures to form and develop the competitiveness of products.

Our proposed set of methods for statistical processing of marketing research data helps to develop measures to form an optimal range of products, identify the weakest positions and develop measures to transfer the real state of the range to the desired level.

\section{References}

1. V. Kumar, R. Leone, D. Aaker, G. Day, Marketing Research, $13^{\text {th }}$ ed. (Wiley, 2019)

2. T.A. Burtseva, Formation and development of integrated marketing information systems (Kirov, 2005)

3. N. Malhotra, Marketing Research: An Applied Orientation, 5th ed., Pearson Education (2010)

4. Water Purifier Market: Global Industry Trends, Share, Size, Growth, Opportunity and Forecast 2021-2026, IMARC Services Pvt. (2021)

5. R.Y. Barreyre, Typologie des innovations, Revue Francaise de Gestion (1980) 
6. C. Ittner, D. Larker, Product Development Cycle Time and Organizational Performance, Journal of Marketing Research (1997)

7. D. Hawkins, R. Best, K. Coney, Consumer Behavior: Building Marketing Strategy, 7th ed. (1998) 